\title{
Raman Evidence of p53-DBD Disorder Decrease upon Interaction with the Anticancer Protein Azurin
}

\author{
Sara Signorelli, Salvatore Cannistraro * ${ }^{*}$ and Anna Rita Bizzarri \\ Biophysics \& Nanoscience Centre, DEB, Università della Tuscia, 01100 Viterbo, Italy; signorellis@unitus.it (S.S.); \\ bizzarri@unitus.it (A.R.B.) \\ * Correspondence: cannistr@unitus.it; Tel.: +39-0761-357136
}

Received: 15 May 2019; Accepted: 20 June 2019; Published: 24 June 2019

\begin{abstract}
Raman spectroscopy, which is a suitable tool to elucidate the structural properties of intrinsically disordered proteins, was applied to investigate the changes in both the structure and the conformational heterogeneity of the DNA-binding domain (DBD) belonging to the intrinsically disordered protein p53 upon its binding to Azurin, an electron-transfer anticancer protein from Pseudomonas aeruginosa. The Raman spectra of the DBD and Azurin, isolated in solution or forming a complex, were analyzed by a combined analysis based on peak inspection, band convolution, and principal component analysis (PCA). In particular, our attention was focused on the Raman peaks of Tyrosine and Tryptophan residues, which are diagnostic markers of protein side chain environment, and on the Amide I band, of which the deconvolution allows us to extract information about $\alpha$-helix, $\beta$-sheet, and random coil contents. The results show an increase of the secondary structure content of DBD concomitantly with a decrease of its conformational heterogeneity upon its binding to Azurin. These findings suggest an Azurin-induced conformational change of DBD structure with possible implications for p53 functionality.
\end{abstract}

Keywords: Raman spectroscopy; p53; intrinsically disordered protein; blue copper protein Azurin; protein-protein interaction; Amide I band deconvolution; principal component analysis

\section{Introduction}

p53 is an important tumor suppressor protein working as a central hub in a complex interaction network in which it regulates numerous cellular processes, including cell cycle progression, apoptosis induction, and DNA repair [1,2]. p53 is a member of the important class of intrinsically disordered proteins (IDPs), possessing both structured and disordered domains under physiological conditions and different conformations coexisting in solution [3]. Such a structural plasticity confers to IDP an extremely high conformational adaptability, allowing them to act according to functional modes not achievable by ordered proteins, with these properties having been recently exploited to develop engineered protein and peptide drugs [4-6].

p53 is a tetrameric protein composed of four identical subunits and acts as a transcription factor. Each monomer of p53 consists of an N-terminal transactivation domain (NTD), a C-terminal domain (CTD), and a core DNA-binding domain (DBD) [7-10] The presence of unstructured portions allows p53 to adopt widely different conformations, which are at the basis of a vast repertoire of available interactions to different biological partners [11]. Among them, Azurin (AZ), a copper-containing electron-transfer anticancer protein secreted by Pseudomonas aeruginosa bacteria, has demonstrated the ability to specifically bind to p53, leading both to its stabilization and to an intracellular level increase both in vitro and in vivo [12-17]. Therefore, the formation of the p53-AZ complex has opened new perspectives in cancer treatment, such as the development of an AZ-derived anticancer peptide [18]. 
Keeping in mind the crucial role of $A Z$ in assisting the oncosuppressive function of $\mathrm{p} 53$, in our group, we investigated the interaction between $\mathrm{p} 53$ and $\mathrm{AZ}$ at the single molecule level by Atomic Force Microscopy (AFM) and Atomic Force Spectroscopy (AFS) and by computational approaches [12,19-21]. These studies have provided information about the interaction kinetics between p53 or its DBD and AZ, obtaining also some relevant insights on the possible binding sites [21]. However, no experimental evidences on possible structural alterations of p53 upon its binding to AZ are so far available [3]. In this respect, Raman spectroscopy represents a suitable approach to extract information about the secondary structure of proteins as well as to probe their conformational heterogeneity, including IDPs [22]. Indeed, we have previously applied such a technique to investigate the structure and the conformational heterogeneity of wild-type and mutants p53 and, also, of the AZ-derived anticancer p28 peptide, even in different environmental conditions [18,23,24].

In the present work, we have employed a Raman-based approach to investigate if and how the native conformation of DBD is modified by its interaction with AZ. To such an aim, we have focused on an accurate inspection of the Fermi doublets relative to Tyrosine (830 and $850 \mathrm{~cm}^{-1}$; Tyr) and of Tryptophan peaks (1340 and $1360 \mathrm{~cm}^{-1}$ ), with these Raman signals having been recognized as suitable diagnostic markers of protein side chain environment $[25,26]$. Additionally, we have investigated the Amide I Raman band (1600-1700 $\left.\mathrm{cm}^{-1}\right)$, of which the deconvolution has demonstrated to be particularly effective in both extracting conformational information ( $\alpha$-helix, $\beta$-sheet, and random coil motifs) and which is a reliable reporter on the structural heterogeneity of proteins [22,27-32]. The Raman spectra have also been analyzed by applying principal component analysis (PCA), which performs a dimensionality reduction of the spectra, allowing a revelation of the differences between the complex Raman spectra of the samples and helping to understand the principal factors affecting the spectral variation [33].

The combination of these approaches has put into evidence the occurrence of structural changes within 553DBD upon its interaction with AZ. In particular, passing from isolated DBD to DBD bound to AZ, we found a variation in Tyrosine (Tyr) and Tryptophan (Trp) residues hydrophobicity and an increase of the DBD secondary structure concomitantly with a significant reduction of the conformational heterogeneity. The observed changes in both the structure and conformational heterogeneity of DBD strongly support the ability of AZ to modulate the DBD structure, and this, in turn, may result in a stabilization of the oncosuppressive function of p53.

\section{Results and Discussion}

\subsection{Raman Analysis of $A Z$ and $D B D$}

Figure 1 shows the Raman spectra of AZ and DBD in the $600-1725 \mathrm{~cm}^{-1}$ frequency range. The spectra display a complex set of bands arising from the modes of the aromatic amino acids (Tyr, Trp, and Phenylalanine (Phe) and of the peptide backbone, consistent with the typical Raman spectra of proteins [27,34]. The assignments of the main peaks are summarized in Table 1 [27].

Table 1. Typical proteins' Raman vibrational modes $\left(\right.$ Raman $\left.\mathrm{cm}^{-1}\right)$ and related assignments.

\begin{tabular}{cc}
\hline Raman $\left(\mathbf{c m}^{\mathbf{- 1}}\right)$ & Assignment \\
\hline 643 & Tyr \\
805 & Tyr \\
830,850 & Tyr \\
870 & Trp \\
902 & $v_{\mathrm{CC}}$ \\
930,980 & $v_{\mathrm{CCN}}$ \\
1001 & Phe \\
1103 & $v_{\mathrm{CC}}, v_{\mathrm{CN}}, v_{\mathrm{CO}}$ \\
1127 & $v_{\mathrm{CC}}$ \\
\hline
\end{tabular}


Table 1. Cont.

\begin{tabular}{cc}
\hline Raman $\left.\mathbf{( c m}^{-\mathbf{1}}\right)$ & Assignment \\
\hline 1174 & Tyr \\
1180 & Phe \\
1210 & Tyr \\
$1230-1240$ & Amide III $(\alpha$-helices $)$ \\
$1250-1255$ & Amide III $(\beta$-sheets $)$ \\
$1270-1300$ & Amide III (Random coils) \\
1320 & $\mathrm{CH}_{2}$ deformation \\
1340,1360 & Trp \\
1403 & ${\text { Symmetric } \nu_{\text {co2 }}^{-}}^{-}$ \\
1424 & $\mathrm{CH}_{2}, \mathrm{CH}_{3}$ deformation \\
1451 & $\mathrm{CH}_{2}, \mathrm{CH}_{3}$ deformation \\
1552 & Trp \\
1604 & Phe \\
1615 & Tyr \\
$1650-1680$ & Amide I \\
\hline
\end{tabular}

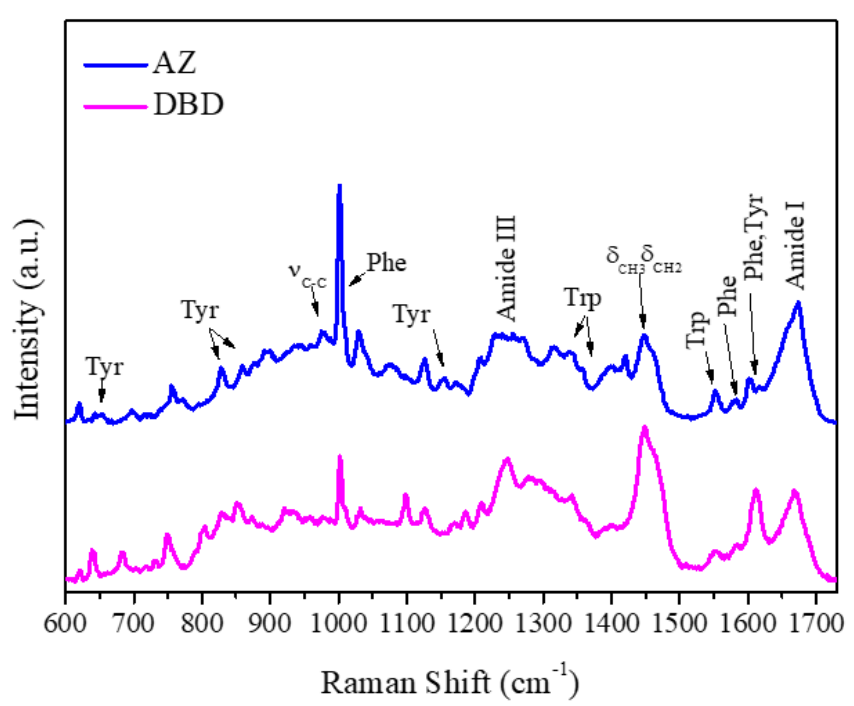

Figure 1. Raman spectra $\left(600-1730 \mathrm{~cm}^{-1}\right)$ with excitation at $532 \mathrm{~nm}$ of Azurin (AZ; blue) and DNA-binding domain (DBD; magenta) in Phosphate Buffer Solution (PBS): The principal proteins' vibrational modes are marked. Spectra were normalized in the all spectrum frequency region and baseline corrected for a better visualization.

Among the main Raman markers, we focused our attention on the Raman peaks of Tyr and Trp residues, which allow the extraction of information on protein side-chain local environment and on the Raman band of Amide I, which provides a diagnostic of the protein secondary structure.

Concerning the Tyr residues, the ratio $\mathrm{I}_{Y}=\mathrm{I}_{850} / \mathrm{I}_{830}$ between the intensity of doublet peaks at 850 and $830 \mathrm{~cm}^{-1}$ is related to the donor or acceptor role of the Tyr phenoxyl group. Specifically, a low $\mathrm{I}_{Y}$ value (around 0.3 ) indicates the phenolic hydroxyl $(\mathrm{OH})$ group acting as a strong hydrogen bond donor, as occurring for buried tyrosine residues. As the $\mathrm{I}_{Y}$ value increases (until 2.5), the phenolic oxygen becomes a stronger hydrogen bond acceptor, while a largely enhanced value ( $\left.\mathrm{I}_{Y}>6.7\right)$ represents a non-hydrogen-bonded state $[25,26]$. Experimental results on isolated AZ reveal an $\mathrm{I}_{Y}$ value of $0.38 \pm 0.07$, representative of a buried environment for its two Tyr residues $\left(\mathrm{Tyr}^{72}\right.$ and $\left.\mathrm{Tyr}^{108}\right)$ in agreement with the $\mathrm{X}$-ray structure of $\mathrm{AZ}$, in which $\mathrm{Tyr}^{72}$ belongs to the peripheral $\alpha$-helix region with a moderate solvent accessibility and $\mathrm{Tyr}^{108}$ is practically inaccessible to solvent (see Figure 2A) [35]. 

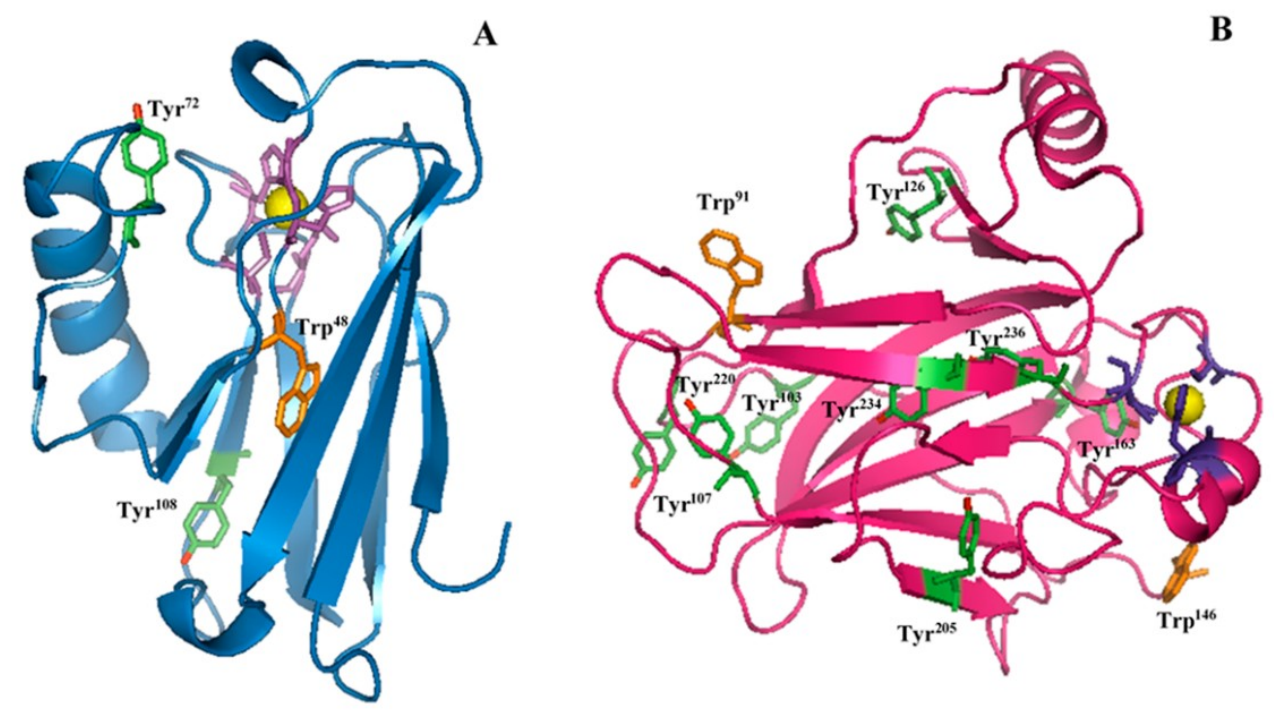

Figure 2. Three-dimensional structures of (A) AZ (PDB code: 4AZU) and (B) DBD (PDB code: 2XWR): The active site of $A Z$ and the zinc-finger of the DBD are shown as yellow ball and stick models. The aromatic residues are Tyr (green) and Trp (orange). The OH groups in Tyr residues are marked in red.

Isolated DBD exhibits an $I_{Y}$ ratio of $1.37 \pm 0.16$, indicating a predominant exposition to the solvent surfaces of the eight Tyr residues. From X-ray structure, the phenolic $\mathrm{OH}$ groups of $\mathrm{Tyr}^{103}$ and $\mathrm{Tyr}^{107}$ are highly oriented towards the solvent (see Figure 2B) [7]. Moreover, $\mathrm{Tyr}^{126}$ and $\mathrm{Tyr}^{205}$, located at a crucial protein region interfacing with the DNA, show moderate accessibility, similar to that of Tyr ${ }^{220}$ located on the surface of the protein [7,8]. Finally, the remaining $\mathrm{Tyr}^{163}, \mathrm{Tyr}^{234}$, and $\mathrm{Tyr}^{236}$ are almost inaccessible to the solvent [8]. Therefore, our results are consistent with the $\mathrm{X}$-ray data endorsing the DBD-Tyr high solvent exposition.

Further information about the side chains can be achieved by analyzing the Fermi doublet bands of Trp residues at 1340 and $1360 \mathrm{~cm}^{-1}$, which are reporters of the hydrophobicity/hydrophilicity neighboring the Trp indole ring [32]. In particular, an intensity ratio $\mathrm{I}_{\mathrm{W}}=\mathrm{I}_{1360} / \mathrm{I}_{1340}$ smaller than 1.0 reflects a hydrophilic environment, while a ratio greater than 1.0 indicates a hydrophobic one [9,32].

For $\mathrm{AZ}$, we found an $\mathrm{I}_{\mathrm{W}}$ ratio of $1.54 \pm 0.10$, indicative of a buried and solvent inaccessible environment for the lone Trp residue. This is in accordance with the AZ X-ray data, showing that the $\operatorname{Tr} \mathrm{p}^{48}$ is deeply embedded in a highly hydrophobic core and surrounded by a closely packed $\beta$ barrel structure (Figure 2A) [35].

We found for DBD an $\mathrm{I}_{\mathrm{W}}$ ratio of $0.68 \pm 0.10$, which implies, on average, a moderate hydrophilic environment for its $\operatorname{Tr}^{91}$ and $\operatorname{Tr} \mathrm{p}^{146}$. The latter is positioned in a hydrophobic side chain and oriented towards the solvent, while the former is located at the N-terminus of DBD and displays a high solvent accessibility, as it comes out from the X-ray data (Figure 2B) [36]. However, $\operatorname{Tr}^{91}$ has been shown to be crucially involved in the packing process of DBD through interaction with the Arg ${ }^{174}$ residue, which reduces its solvent exposure [36]. Therefore, our data suggest that both Trp residues in DBD globally experience a hydrophilic environment.

Information on protein secondary structure can be extracted by the Amide I band $\left(1600-1700 \mathrm{~cm}^{-1}\right)$, mainly arising from $\mathrm{C}=\mathrm{O}$ stretching and the combination of the $\mathrm{C}-\mathrm{N}$ stretching, the $\mathrm{C} \alpha-\mathrm{C}-\mathrm{N}$ bending, and the N-H in-plane bending modes of peptide group. Such a band is usually used as a marker for secondary structure components. In particular, when Amide I band is centered at $1655 \mathrm{~cm}^{-1}$, it indicates a prevailing $\alpha$-helix conformational arrangement, while a shift of this band peak toward $1670 \mathrm{~cm}^{-1}$ is indicative of $\beta$-sheet conformation [22]. On the other hand, an analysis of the Amide I shape means an appropriate deconvolution strategy allows for the quantification of the percentage content of secondary structure components present in the protein [22,28]. 
Specifically, the Amide I band of AZ emerges at about $1670 \mathrm{~cm}^{-1}$ (Figure 3A), suggesting a predominant $\beta$-sheet conformation [37]. The curve-fitting procedure points out $\beta$-sheet conformations predominant for $60 \%$, while the $\alpha$-helices and random coils account for about $22 \%$ and $18 \%$, respectively. The obtained AZ secondary structure is agreement with that determined by $X$-ray diffraction for the crystals of AZ. Indeed, the major AZ components are $\beta$ strands and turns $(\approx 69 \%)$, which form two sheets arranged in a Greek key motif and with a minor contribution from a rigid $\alpha$-helix (about $31 \%$ ), conferring to AZ a low level of flexibility and structural disorder (see Figure $3 \mathrm{~A})[21,35,38]$.
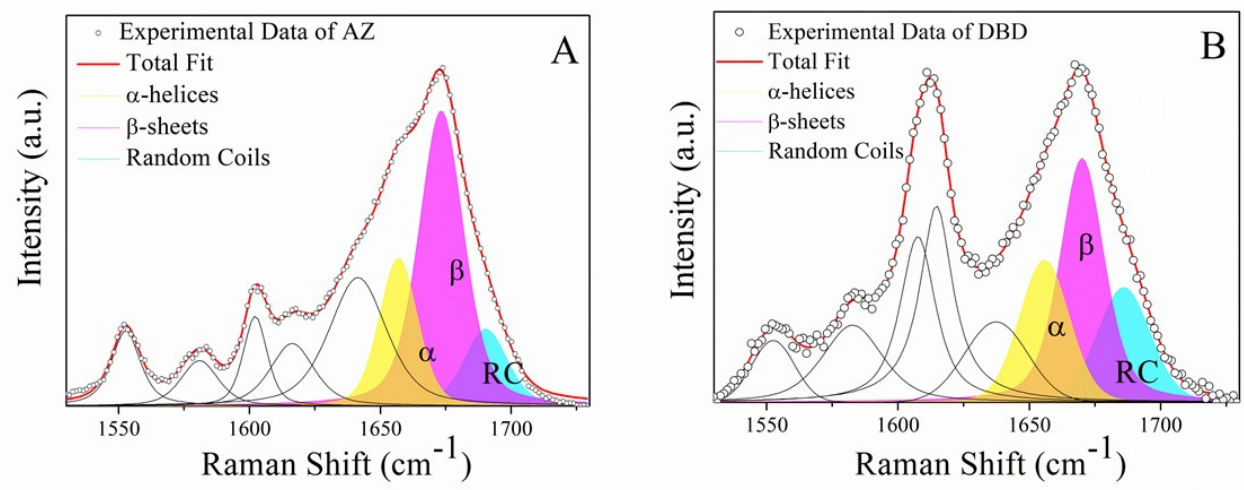

Figure 3. The Amide I band of AZ (A) and DBD (B) in PBS: The percentage of secondary structure for these proteins has been estimated from the relative area of deconvoluted bands of this spectral region of which the fitting parameters are reported in Table 2.

Table 2. Assignments, relative central frequency $\left(\right.$ Raman $\mathrm{cm}^{-1}$ ), and integrated intensities (Area \%) of the main Amide I band components ( $\alpha$-helix, $\beta$-sheet, or random coil) for AZ, DBD, and DBD:AZ complex obtained by a fitting procedure. $\chi^{2}=0.002$ for all curve fitting analysis.

\begin{tabular}{cccc}
\hline Sample In PBS & Secondary Structure & Raman Shift $\mathbf{c m}^{\mathbf{- 1}}$ & Area (\%) \\
\hline \multirow{2}{*}{ AZ } & $\alpha$-helix & 1659 & 22 \\
& $\beta$-sheet & 1674 & 60 \\
\multirow{2}{*}{ DBD } & random coil & 1688 & 18 \\
& $\alpha$-helix & 1655 & 25 \\
& $\beta$-sheet & 1670 & 46 \\
DBD:AZ & random coil & 1686 & 29 \\
& $\alpha$-helix & 1655 & 26 \\
& $\beta$-sheet & 1669 & 51 \\
& random coil & 1687 & 23 \\
\hline
\end{tabular}

Concerning DBD (Figure 3B), the band corresponding to the $\beta$-structures provides $46 \%$ of the total, while those related to $\alpha$-helix and to random coils have $25 \%$ and $29 \%$, respectively. These results indicate that DBD is characterized by a partially ordered structure, combined with the presence of significant disordered regions. Additionally, the results confirm those reported in our recent study on different sample batches of DBD (aminoacids 81-300), from which a content of $27 \%$ and $50 \%$ for $\alpha$-helical and $\beta$ conformations, respectively, have been estimated [23]. Moreover, these data are in agreement with X-ray data indicating a $30 \%$ of $\beta$-arrangement with an $18 \%$ of $\alpha$-structures (see Figure 3B) [36]. The DBD propensity to adopt a predominant $\beta$-conformation is actually related to the large presence in its sequence of hydrophobic residues, such as Cysteine (Cys), Trp, and Leucine (Leu), generally promoting an ordered structure [39].

\subsection{Raman Analysis of the $D B D: A Z$ Complex}

The previous analysis on the Raman spectra of AZ and DBD proteins, isolated in solution, has provided information on their structural properties paving the way to investigate possible structural 
change when they are involved in the formation of a complex. The spectrum of DBD:AZ solution, obtained by mixing equimolar amounts of DBD and AZ in the $600-1725 \mathrm{~cm}^{-1}$ frequency region is shown in Figure 4. We note almost the same general features displayed by the isolated protein spectra with no significant shifts in frequency for the main vibrational modes. From the Tyr peaks visible at 828 and $854 \mathrm{~cm}^{-1}$, the Fermi doublet ratio $\mathrm{I}_{Y}$ is $0.58 \pm 0.08$, which is indicative of a predominant hydrophobic environment. Such a value is closer to that of $A Z\left(I_{Y}=0.38 \pm 0.07\right)$ with respect to that of $\mathrm{DBD}\left(\mathrm{I}_{Y}=1.37 \pm 0.16\right)$, suggesting some changes in the Tyr microenvironment resulting from the interaction between the two biomolecules. To further support such a hypothesis, we have analyzed the Raman spectrum obtained by directly summing the spectra of isolated DBD and AZ molecules acquired at the same concentration used to form the complex (Figure 4), with the resulting spectrum being called added spectrum (AS) in the following. The analysis of the Tyr peaks in the AS spectrum reveals an $\mathrm{I}_{Y}$ of $1.11 \pm 0.18$, which is indicative of an average hydrophilic environment for all the Tyr residues in the system, as expected for isolated proteins. Therefore, the marked differences between the $\mathrm{I}_{Y}$ values from the complex and AS spectra can be ascribed to changes due to the interaction between the molecules. Although the spectroscopic results alone cannot allow us to identify the Tyrs that are involved in the structural changes, they support literature data that point out the involvement of the $\mathrm{S}_{7}-\mathrm{S}_{8}$ loops, comprising $\mathrm{Tyr}^{220}, \mathrm{Tyr}^{234}$, and $\mathrm{Tyr}^{236}$ and also $\mathrm{Tyr}^{126}$ at DBD binding sites with $\mathrm{AZ}$, which, in turn, is engaged through its a.a 50-77 fragment, including Tyr ${ }^{72}$ [40].

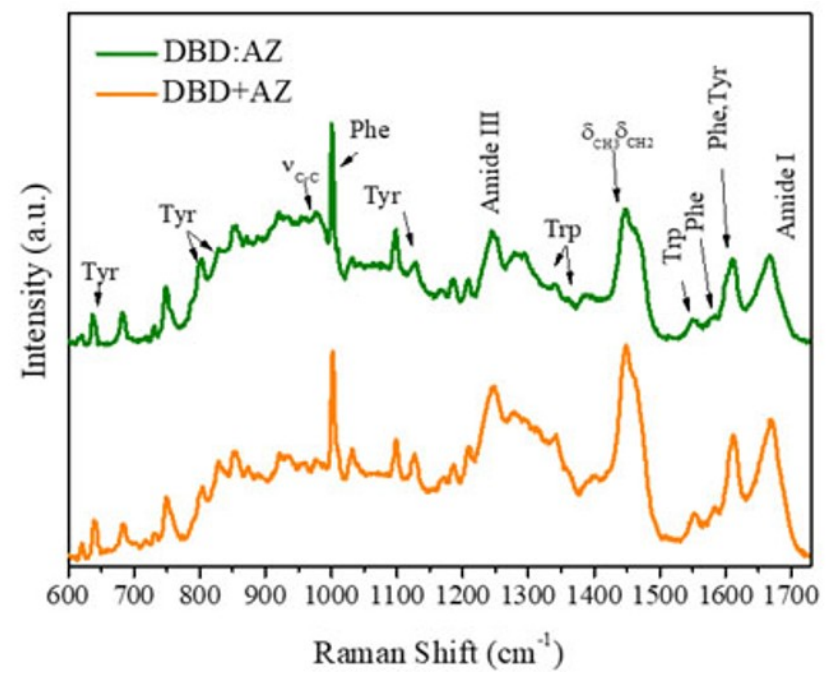

Figure 4. Comparison among the 532-nm-excited Raman spectra $\left(600-1730 \mathrm{~cm}^{-1}\right)$ of DBD:AZ complex (green) and of added spectrum AS (orange) in PBS: The principal proteins' vibrational modes are marked. Spectra were normalized in the all spectrum frequency region and baseline corrected for a better visualization.

The spectrum of DBD:AZ shows that the Trp Raman peaks are located at the same frequencies as in the isolated proteins, with an $\mathrm{I}_{\mathrm{W}}$ ratio of $1.15 \pm 0.17$, indicating a high hydrophobicity for the three Trps residues (AZ-Trp ${ }^{48}$ and DBD-Trp ${ }^{91} / \operatorname{Trp}^{146}$ ). The found value of $\mathrm{I}_{\mathrm{W}}$ for DBD:AZ, slightly lower than that for AZ $\left(I_{W}=1.54 \pm 0.10\right)$ and higher than both isolated $\mathrm{DBD}\left(\mathrm{I}_{\mathrm{W}}=0.68 \pm 0.10\right)$ and AS $\left(\mathrm{I}_{\mathrm{W}}=0.53 \pm 0.10\right)$, suggests some modifications in the environment experienced by these residues upon complex formation. The AZ-Trp ${ }^{48}$ is well-known to be strongly buried in the central hydrophobic core of the AZ; therefore, these changes can be due to variations in the DBD-Trp neighboring. Additionally, since the DBD-Trp ${ }^{91}$ has been shown to be engaged with the $\operatorname{Arg}^{174}$ [36], we suggest that the observed modifications of DBD as due to AZ interactions occurring within the DBD-Trp ${ }^{146}$ environment, with this being in agreement with Docking and Molecular Dynamics (MD) data showing the involvement of $\operatorname{Trp}^{146}$ in AZ-binding site [40]. 
Figure 5A,B shows the fitted curves of the Amide I band for the DBD:AZ and AS spectra, respectively. The results of the best fit for both experimental and AS Amide I bands, obtained by applying the same method used for isolated molecules, are reported in Table 2. DBD:AZ shows a predominant contribution from $\beta$-sheet structures $(51 \%)$ and an $\alpha$-helix amount of about $26 \%$, while the random coil conformations contributes to $23 \%$ of the total Amide I band area. Best fit of AS reveals a predominant $\beta$ structure (41\%) with $\alpha$-helices and random coils percentages of $31 \%$ and $28 \%$, respectively. The observed changes in the secondary structure composition in DBD:AZ with respect to those of $\mathrm{DBD}$ and $\mathrm{AZ}$ can be attributed to the interaction between these proteins. Furthermore, since $\mathrm{AZ}$ is characterized by a highly structured conformation, the decrease of random coil structures can be mainly attributed to DBD. Such a result is supported by previously reported molecular dynamics simulations and docking studies showing that the binding of $\mathrm{AZ}$ at the peripheral, unstable, $\mathrm{L}_{1}$ and $\mathrm{S}_{7}-\mathrm{S}_{8}$ loops of DBD can enhance their stability upon restraining their flexibility [21], with this being in agreement with a reduction of the DBD disordered regions upon binding to AZ. Accordingly, it could be hypothesized that the increase of structural stability of DBD could be at the basis of the anticancer effect exerted by AZ. Since the structural dynamics and the interactions between proteins are strictly connected, a deeper characterization of the structural-functional relations is of fundamental interest for developing AZ-based drugs, of which effective action in vivo requires, however, further validations [41].
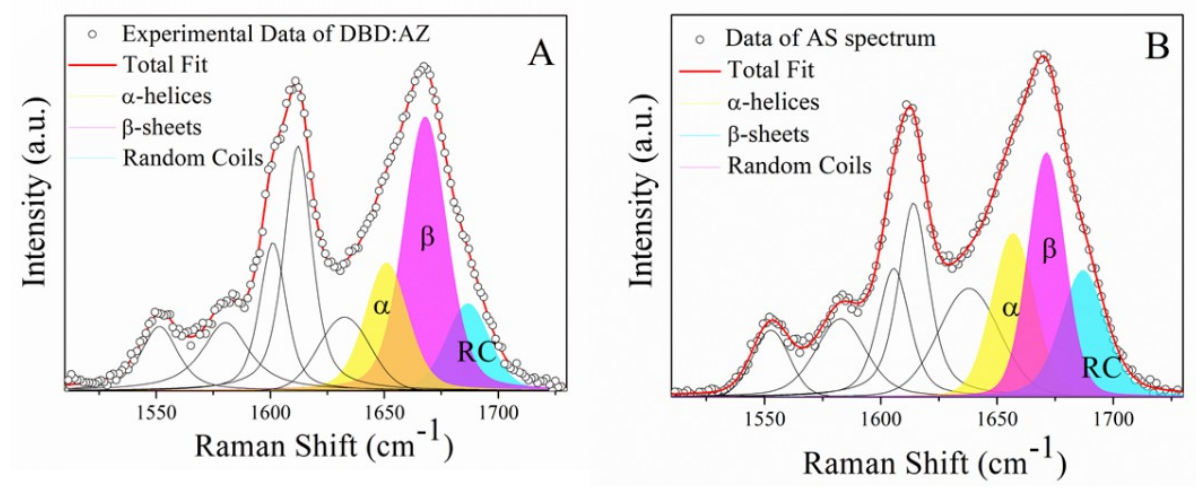

Figure 5. Amide I Raman band (open circles) excited at $532 \mathrm{~nm}$ of (A) DBD:AZ and (B) AS spectra, fitted through the Levenberg-Marquardt minimization algorithm (LMA; red line) in which the AZ total fit has been imposed as a constraint: Solid curves indicate the main structural conformations ( $\alpha$-helices, $\beta$-sheets, and random coils). Fitting results are summarized in Table 2.

\subsection{Principal Component Analysis of $D B D, A Z$, and the $D B D: A Z$ Complex}

Different combinations of scores for the first three principal components (PC1, PC2, and PC3) have been used to build two-dimensional plots; in the following, the components releasing the highest structural information will be shown. Figure 6A shows the PCA scores of PC1 vs. PC2 components (providing about the $90 \%$ of the total variance) for the Fermi Doublet region relative to Tyr residues (790-870 $\mathrm{cm}^{-1}$ ) for the AZ and DBD isolated molecules and for the DBD:AZ complex. In the scatter plot, two distinct groupings along the PC1 axis can be identified (see the ellipses drawn as a guide). Indeed, the AZ scores (blue symbols) are located in the positive portion of the plot along PC1 with a low spread along both the axes (10 and 5 along PC1 and PC2, respectively), while the DBD and DBD:AZ scores (magenta and green symbols, respectively) occupy the negative range of $P C 1$ values. Along $\mathrm{PC1}$, a larger variability is detected for DBD with respect to AZ and DBD:AZ. Additionally, along PC2, for $\mathrm{AZ}$ and $\mathrm{DBD}$, negative values of $\mathrm{PC} 2$ are obtained while positive values are detected for DBD. To correlate the position of the scores in the plot with the samples' spectral features, we have analyzed the loadings with the variables mostly contributing to the PCA scores. As shown in Figure 6B,C, high levels of variance are detected in correspondence with the peaks at $829 \mathrm{~cm}^{-1}$ and $851 \mathrm{~cm}^{-1}$ related to the Fermi Doublet of Tyr modes and with a weaker peak at $805 \mathrm{~cm}^{-1}$, associated with Tyr [25,32,42]; 
the latter provides the largest variance for PC2 loadings (see Figure 6B) [42]. These results show that Tyr vibrational modes are responsible for sample differentiation in PCA, consistent with our previous study supporting the important role played by Tyr modes as structural markers [25,42].
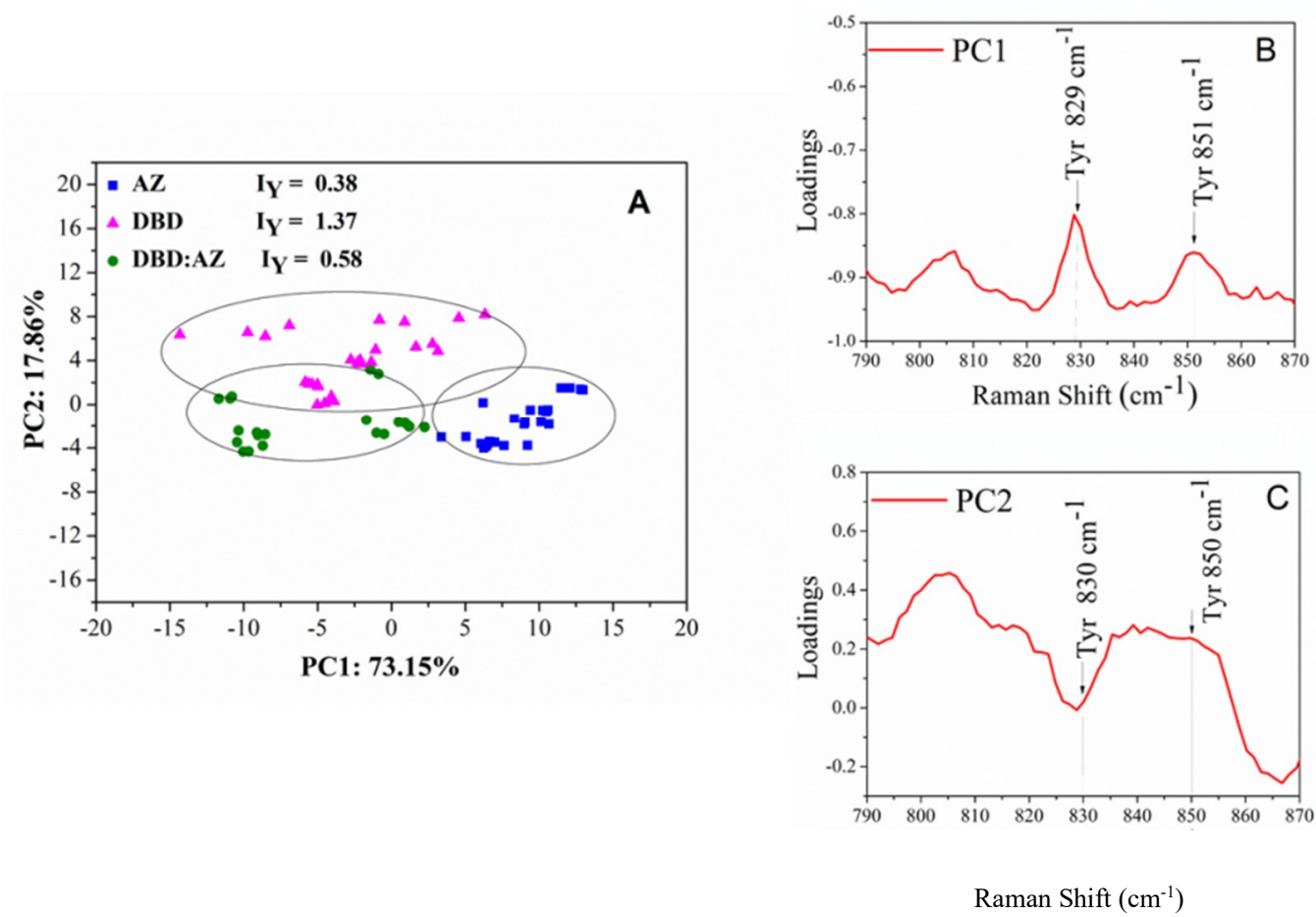

Figure 6. (A) Two-dimensional scores plot PC1 versus PC2 of the Raman spectra for AZ (blue squares), DBD (magenta triangles), and DBD:AZ complex (green circles) in the PBS performed on Fermi Doublet of Tyr region (790-870 $\left.\mathrm{cm}^{-1}\right)$ : The three groupings are indicated by ellipses. The Fermi Doublet ratio for Tyr residues are also reported. (B) PC1 (73\% of total variance) and (C) PC2 (18\% of total variance) one-dimensional loadings plot versus frequency. The Raman markers are indicated.

We then applied PCA to the Fermi Doublet region relative to Trp residues $\left(1310-1380 \mathrm{~cm}^{-1}\right)$, with the PC1 and PC2 components providing about $91 \%$ of the total variance (see Figure $7 \mathrm{~A})$. AZ clusters at the upper side, DBD clusters at the middle, while DBD:AZ clusters at the lower region in correspondence to negative values of PC2 axis. Along PC1, DBD, and DBD:AZ, scores are mixed within an overlapped cloud, while AZ are well-clustered in a well-separated group. Concerning the loading plots, shown in Figure 8B,C, PC2 presents a broad band with a loading positive value of about 0.2. At $1360 \mathrm{~cm}^{-1}$, a single evident peak emerges as ascribed to one of the Fermi Doublet of the Trp modes. This suggests that the separation among the three groups along PC2 depends on Trp vibrational modes. Since such a frequency changes according to the different Trp side-chain environment taken into consideration [28], a different spatial arrangement of this residue should be envisaged in the DBD isolated molecule and in DBD:AZ complex. 

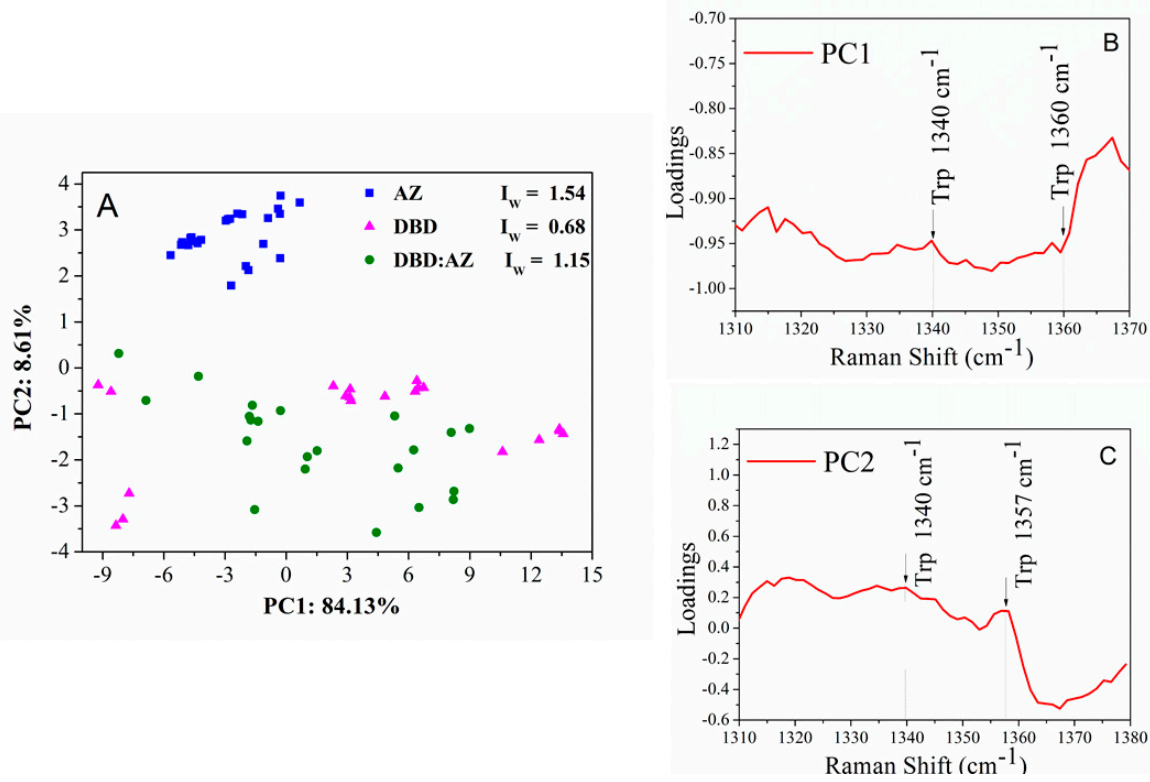

Figure 7. (A) Two-dimensional scores plot PC1 versus PC2 of the Raman spectra for AZ (blue squares), DBD (magenta triangles), and DBD:AZ complex (green circles) in the PBS performed on Fermi Doublet of Trp region (1310-1380 $\mathrm{cm}^{-1}$ ): The Fermi Doublet ratio for Tyr residues are also reported. (B) PC1 (84\% of total variance) and (C) PC2 (8\% of total variance) one-dimensional loadings plot versus frequency. The Raman markers are indicated.
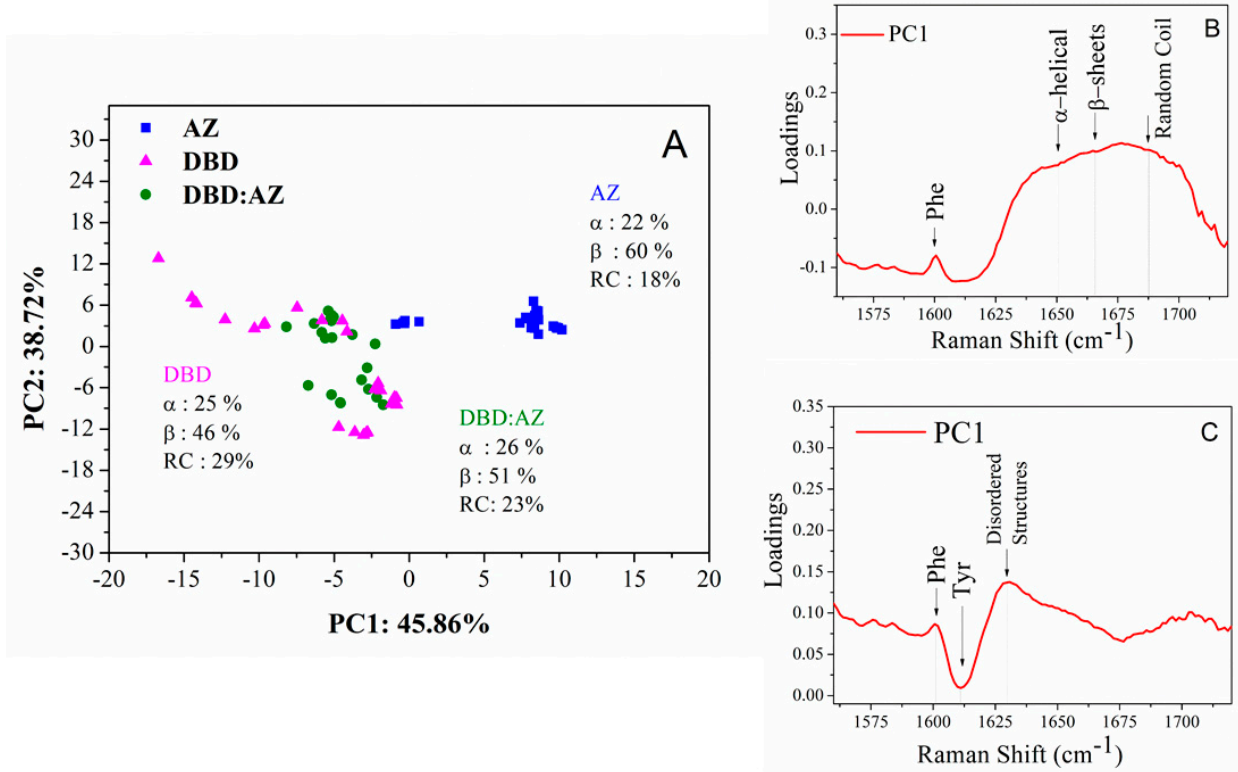

Figure 8. (A) Two-dimensional scores plot PC1 versus PC2 of the Raman spectra for AZ (blue squares), DBD (magenta triangles), and DBD:AZ complex (green circles) in the PBS performed on the Amide I band (1560-1720 $\left.\mathrm{cm}^{-1}\right)$ : The secondary structure percentages as obtained by the curve fitting analysis are also reported. (B) PC1 (46\% of total variance) and (C) PC2 (39\% of total variance) one-dimensional loadings plot versus frequency. The Raman markers are indicated.

Finally, the PCA was performed on the Amide I Raman band of AZ, DBD, and the DBD:AZ complex. From the scatter plot of PC1 versus PC2 (see Figure 8A), AZ data (blue squares) cluster at the positive side of the PC1 axis, with a low variance along both of the components, while DBD (magenta triangles) and DBD:AZ data (green circles) are characterized by negative values of PC1, with some 
overlap between them. A significantly larger variability is detected in DBD with respect to that of DBD:AZ.

The PC1 loading curve, accounting for $46 \%$ of the variance (Figure $8 \mathrm{~B}$ ), is characterized by a very broad band from 1625 to $1730 \mathrm{~cm}^{-1}$, including all the frequencies related to the secondary structure of a protein. Such a band shows the lowest value for the $1650 \mathrm{~cm}^{-1}$ frequency and the highest for the 1680 $\mathrm{cm}^{-1}$ one, which are associated to the $\alpha$-helices and disordered structures, respectively $[19,24]$. In PC2, accounting for a $39 \%$ of the variation in the spectra, the major source of variance comes from peak at $1627 \mathrm{~cm}^{-1}$, consistent with the disordered structures component (Figure 8C) [19]. This indicates that PC1 discriminates the data based on different amounts of secondary structure of the sample, while PC2 reflects the amount of conformational disorder. Indeed, the AZ scores are very close to each other, indicating a very low variability in the secondary structure within different batches of samples, with this being consistent with the AZ ordered secondary structure [32]. Additionally, the superposition of DBD and DBD:AZ data along PC1 can be explained by assuming that the intrinsic disordered nature of DBD is able to populate an ensemble of different conformations. On the other hand, DBD:AZ distribution on the plot is narrower than that of $D B D$, reflecting a lower degree of disorder in the complex. These results confirm that PCA is a good reporter of the different structural differences among $\mathrm{AZ}, \mathrm{DBD}$, and DBD:AZ. Moreover, PCA is sensitive to changes in the conformational heterogeneity of $\mathrm{DBD}$ in the presence of $\mathrm{AZ}$.

\section{Materials and Methods}

\subsection{Sample Preparation}

$\mathrm{AZ}$ (purity $>80 \%$; $\mathrm{MW}=14.6 \mathrm{kDa}$ ) was purchased from Sigma-Aldrich (St. Louis, MO, USA). The effective purity of the sample was checked by determining the ratio of spectral absorption at $630 \mathrm{~nm}$ and at $280 \mathrm{~nm}$. AZ batches with a ratio value higher than 0.48 were used, with this indicating a good degree of purity [43]. AZ was dissolved in MilliQ water at a concentration of $200 \mu \mathrm{M}$. DBD (a.a 89-293; MW= $23 \mathrm{kDa}$ ) was purchased from GenScript (Piscataway, NJ, USA). DBD were dissolved in Phosphate Buffer Solution (PBS; $95.3 \% \mathrm{H}_{2} \mathrm{O}, 3.8 \% \mathrm{NaCl}, 0.1 \%$ di $\mathrm{KCl}, 0.7 \% \mathrm{Na}_{2} \mathrm{HPO}_{4}, 0.1 \% \mathrm{KH}_{2} \mathrm{PO}_{4}$; $\mathrm{pH}=7.4$ ), reaching a final concentration of $40 \mu \mathrm{M}$. The DBD:AZ complex in PBS solution were prepared by mixing equimolar amounts of the components.

\subsection{Raman Spectroscopy}

Raman measurements were carried out using a Super Labram confocal spectrometer (Horiba, France), equipped with several objectives, a diode-pumped solid-state laser $(532 \mathrm{~nm})$ and a spectrograph, with an $1800 \mathrm{~g} / \mathrm{mm}$ grating allowing a resolution of $5 \mathrm{~cm}^{-1}$. Raman spectra were collected by means of a liquid nitrogen-cooled charged coupled device (CCD) (back illuminated; pixel format: $1024 \times 128$ detector) and in the back-scattering geometry in which a notch filter was used to reject the elastic contribution. All the experiments were performed using a laser power of $10 \mathrm{~mW}(4.4 \mathrm{~mW}$ on the sample) and a $50 \times$ objective with a numerical aperture NA $=0.6$ (laser spot diameter reaching the sample was about $1 \mu \mathrm{m})$. A large confocal diaphragm $(400 \mu \mathrm{m})$ and a slit of $200 \mu \mathrm{m}$ were used to obtain a good Raman signal.

Protein drops (10-15 $\mu \mathrm{L})$ were deposited onto an optical glass, and spectra were acquired on partially dried samples. Indeed, it was demonstrated that there are no significant differences between the Raman spectra of protein in solution and the corresponding drop coating deposition, in which the protein remains substantially hydrated and the secondary structure is largely preserved [44].

Each Raman spectrum was acquired at room temperature by averaging 10 scans of $10 \mathrm{~s}$ integration time. For each sample, twenty-five Raman spectra were collected from different regions of the drops. Raman data processing and analysis were performed with OPUS software version 6.5 (Bruker Optics, Ettlingen, Germany). All the spectra were normalized with respect to the phenylalanine (Phe) ring breathing band at $1002 \mathrm{~cm}^{-1}$ due to its insensitivity to conformation or microenvironment [45], and the 
fluorescence background was removed by applying a rubber band baseline correction [46]. Finally, the spectra used for the structural analysis were obtained by averaging five measurements to improve the spectral signal/noise ratio.

\subsection{Analysis of the Raman Spectra}

The secondary structure content of isolated DBD and AZ was quantified through a deconvolution procedure of the Amide I Raman bands by using three pseudo-Voigt profiles. The model parameters were optimized with the Levenberg-Marquardt minimization algorithm (LMA), and the goodness of the fit was assessed by the reduced chi-square value. The AZ curves as extracted from the fit were used in the DBD:AZ complex analysis, under the hypothesis that the AZ secondary structure does not change upon the interaction [38]. The three pseudo-Voigt profiles were centered at 1650-1656, 1664-1670, and $1680 \mathrm{~cm}^{-1}$ and assigned to $\alpha$-helix, $\beta$-strand, and random coil conformations, respectively, as validated on other IDPs $[22,23,27]$. In each fitting analysis, additional peaks had to be included in the band-fitting protocol to account for aromatic residue modes $\left(1550,1580,1604\right.$, and $\left.1615 \mathrm{~cm}^{-1}\right)$ and for disordered structure and/or vibronic coupling $\left(1637 \mathrm{~cm}^{-1}\right)$ not baseline separated from Amide I features [22]. The errors relative to secondary structure percentages were evaluated by repeating the curve-fitting procedure on five different spectra and the accuracy associated with the determined secondary structure content was about $10 \%$ for each sample.

In order to improve the performance of deconvolution analysis, we performed a dimensionality reduction of the Raman spectra based on principal component analysis (PCA) [33]. The PCA transforms the original data set into a new data set with transformed variables (principal components) that are linear combinations of the original variables. The principal components were arranged in a swat that the variability of the original data set was contained in descending order in the first principal components. PCA was applied to the isolated DBD and AZ molecules and to the DBD:AZ complex (number of spectra $n=75$ ) in three different spectral regions: (i) Fermi doublets relative to Tyr (830 and $850 \mathrm{~cm}^{-1}$ ), satisfactorily described by a number of components $\mathrm{N}=79$; (ii) Fermi doublets relative to $\operatorname{Trp}$ (1340 and $1360 \mathrm{~cm}^{-1}$ ) described by $\mathrm{N}=79$; and (iii) Amide I Raman band $\left(1600-1700 \mathrm{~cm}^{-1}\right)$ described by $\mathrm{N}=77$. The number of components of the correlation matrix to be considered was defined as the number required to explain at least $80 \%$ of the total variance. STATISTICA 7.0 software (StatSoft Inc., Tulsa, OK, USA, 2004) was used for all the analyses.

\section{Conclusions}

The structural and conformational changes in the DBD region of the intrinsically disordered protein p53 upon interacting with the anticancer blue copper protein $\mathrm{AZ}$ were investigated by applying Raman spectroscopy. A careful inspection of the Raman spectra combined with a PCA analysis on the Fermi doublets of the Raman markers corresponding to the tyrosine and tryptophan residues allowed us to monitor the changes in their microenvironment as induced by the formation of a complex between DBD and AZ. Interestingly, we found a direct involvement of DBDTrp ${ }^{146}$ in the complex formation, as suggested by other experimental investigations. Additionally, a deconvolution of the Amide I band, remarkably sensitive to the $\alpha$-helix, $\beta$-sheets, and random coil structures, allowed us to quantify the main secondary structural motifs of the DBD and its changes as induced upon binding to AZ. We found that DBD undergoes a slight increase of the $\beta$-conformation, with a concomitant lowering of its disordered portions as well as of its conformational heterogeneity. These findings are in agreement with our previous computational results and suggest that the binding of $\mathrm{AZ}$ to some unstructured motifs of DBD can restrain their flexibility. Collectively, the observed modulation the DBD structure when bound to $\mathrm{AZ}$ may represent a ground for understanding the molecular mechanisms of the $\mathrm{AZ}$ anticancer activity and could provide some hints for designing other molecules for p53-targeted therapies. Finally, we would remark that our Raman-based approach can be applied to investigate the structural changes of other biomolecules undergoing specific complex formation in order also to elucidate the molecular mechanisms which regulate their biological functions. 
Author Contributions: S.S. data curation, formal analysis, investigation, and writing—original draft preparation; S.C. and A.R.B. writing - review and editing; S.C. and A.R.B. conceptualization supervision.

Funding: This research was funded by the Italian Association for Cancer Research (AIRC) Grant IG15866 to S.C.

Conflicts of Interest: The authors declare no conflict of interest.

\section{References}

1. Vousden, K.H.; Lane, D.P. p53 in health and disease. Nat. Rev. Mol. Cell Biol. 2007, 8, 275-283. [CrossRef] [PubMed]

2. Kruiswijk, F.; Labuschagne, C.F.; Vousden, K.H. p53 in survival, death and metabolic health: A lifeguard with a licence to kill. Nat. Rev. Mol. Cell Biol. 2015, 16, 393-405. [CrossRef] [PubMed]

3. Uversky, V.N. Unusual biophysics of intrinsically disordered proteins. Biochim. Biophys. Acta (BBA)-Proteins Proteom. 2013, 1834, 932-951. [CrossRef] [PubMed]

4. Tompa, P. Intrinsically unstructured proteins. Trends Biochem. Sci. 2002, 27, 527-533. [CrossRef]

5. Habchi, J.; Tompa, P.; Longhi, S.; Uversky, V.N. Introducing Protein Intrinsic Disorder. Chem. Rev. 2014, 114, 6561-6588. [CrossRef] [PubMed]

6. Minde, D.P.; Halff, E.F.; Tans, S. Designing disorder. Intrinsically Disord. Proteins 2013, 1, e26790. [CrossRef] [PubMed]

7. Cañadillas, J.M.P.; Tidow, H.; Freund, S.M.V.; Rutherford, T.J.; Ang, H.C.; Fersht, A.R. Solution structure of p53 core domain: Structural basis for its instability. Proc. Natl. Acad. Sci. USA 2006, 103, 2109-2114. [CrossRef]

8. Cho, Y.; Gorina, S.; Jeffrey, P.D.; Pavletich, N.P. Crystal structure of a p53 tumor suppressor-DNA complex: Understanding tumorigenic mutations. Science 1994, 265, 346-355. [CrossRef]

9. Pagano, B.; Jama, A.; Martinez, P.; Akanho, E.; Bui, T.T.T.; Drake, A.F.; Fraternali, F.; Nikolova, P.V. Structure and stability insights into tumour suppressor p53 evolutionary related proteins. PLoS ONE 2013, 8, e76014. [CrossRef]

10. Bell, S.; Klein, C.; Müller, L.; Hansen, S.; Buchner, J. P53 Contains Large Unstructured Regions in Its Native State. J. Mol. Biol. 2002, 322, 917-927. [CrossRef]

11. Berlow, R.B.; Dyson, H.J.; Wright, P.E. Functional advantages of dynamic protein disorder. FEBS Lett. 2015, 589, 2433-2440. [CrossRef]

12. Punj, V.; Das Gupta, T.K.; Chakrabarty, A.M. Bacterial cupredoxin azurin and its interactions with the tumor suppressor protein p53. Biochem. Biophys. Res. Commun. 2003, 312, 109-114. [CrossRef]

13. Yamada, T.; Goto, M.; Punj, V.; Zaborina, O.; Chen, M.L.; Kimbara, K.; Majumdar, D.; Cunningham, E.; Das Gupta, T.K.; Chakrabarty, A.M. Bacterial redox protein azurin, tumor suppressor protein p53, and regression of cancer. Proc. Natl. Acad. Sci. USA 2002, 99, 14098-14103. [CrossRef]

14. Goto, M.; Yamada, T.; Kimbara, K.; Horner, J.; Newcomb, M.; Gupta, T.K.; Chakrabarty, A.M. Induction of apoptosis in macrophages by Pseudomonas aeruginosa azurin: Tumour-suppressor protein p53 and reactive oxygen species, but not redox activity, as critical elements in cytotoxicity. Mol. Microbiol. 2003, 47, 549-559. [CrossRef]

15. Yamada, T.; Hiraoka, Y.; Ikehata, M.; Kimbara, K.; Avner, B.S.; Das Gupta, T.K.; Chakrabarty, A.M. Apoptosis or growth arrest: Modulation of tumor suppressor p53's specificity by bacterial redox protein azurin. Proc. Natl. Acad. Sci. USA 2004, 101, 4770-4775. [CrossRef]

16. Yamada, T.; Fialho, A.M.; Punj, V.; Bratescu, L.; Gupta, T.K.; Chakrabarty, A.M. Internalization of bacterial redox protein azurin in mammalian cells: Entry domain and specificity. Cell. Microbiol. 2005, 7, 1418-1431. [CrossRef]

17. Yamada, T.; Gupta, E.; Beattie, C.W. p28-Mediated Activation of p53 in G2-M Phase of the Cell Cycle Enhances the Efficacy of DNA Damaging and Antimitotic Chemotherapy. Cancer Res. 2016, 76, $2354-2365$. [CrossRef]

18. Signorelli, S.; Santini, S.; Yamada, T.; Bizzarri, A.R.; Beattie, C.W.; Cannistraro, S. Binding of Amphipathic Cell Penetrating Peptide p28 to Wild Type and Mutated p53 as studied by Raman, Atomic Force and Surface Plasmon Resonance spectroscopies. Biochim. Biophys Acta Gen. Subj. 2017, 1861, 910-921. [CrossRef] 
19. Domenici, F.; Frasconi, M.; Mazzei, F.; D'Orazi, G.; Bizzarri, A.R.; Cannistraro, S. Azurin modulates the association of Mdm2 with p53: SPR evidence from interaction of the full-length proteins. J. Mol. Recognit. 2011, 24, 707-714. [CrossRef]

20. Funari, G.; Domenici, F.; Nardinocchi, L.; Puca, R.; D’Orazi, G.; Bizzarri, A.R.; Cannistraro, S. Interaction of p53 with Mdm2 and azurin as studied by atomic force spectroscopy. J. Mol. Recognit. 2010, 23, 343-351. [CrossRef]

21. De Grandis, V.; Bizzarri, A.R.; Cannistraro, S. Docking study and free energy simulation of the complex between p53 DNA-binding domain and azurin. J. Mol. Recognit. 2007, 20, 215-226. [CrossRef]

22. Maiti, N.C.; Apetri, M.M.; Zagorski, M.G.; Carey, P.R.; Anderson, V.E. Raman spectroscopic characterization of secondary structure in natively unfolded proteins: Alpha-synuclein. J. Am. Chem. Soc. 2004, 126, 2399-2408. [CrossRef]

23. Signorelli, S.; Cannistraro, S.; Bizzarri, A.R. Structural Characterization of the Intrinsically Disordered Protein p53 Using Raman Spectroscopy. Appl. Spectrosc. 2016, 71, 823-832. [CrossRef]

24. Yamada, T.; Signorelli, S.; Cannistraro, S.; Beattie, C.W.; Bizzarri, A.R. Chirality switching within an anionic cell-penetrating peptide inhibits translocation without affecting preferential entry. Mol. Pharm. 2015, 12, 140-149. [CrossRef]

25. Siamwiza, M.N.; Lord, R.C.; Chen, M.C.; Takamatsu, T.; Harada, I.; Matsuura, H.; Shimanouchi, T. Interpretation of the doublet at 850 and $830 \mathrm{~cm}-1$ in the Raman spectra of tyrosyl residues in proteins and certain model compounds. Biochemistry 1975, 14, 4870-4876. [CrossRef]

26. Arp, Z.; Autrey, D.; Laane, J.; Overman, S.A.; Thomas, G.J. Tyrosine Raman signatures of the filamentous virus Ff are diagnostic of non-hydrogen-bonded phenoxyls: Demonstration by Raman and infrared spectroscopy of p-cresol vapor. Biochemistry 2001, 40, 2522-2529. [CrossRef]

27. Tuma, R. Raman spectroscopy of proteins: From peptides to large assemblies. J. Raman Spectrosc. 2005, 36, 307-319. [CrossRef]

28. Torreggiani, A.; Fini, G. Raman spectroscopic studies of ligand-protein interactions: The binding of biotin analogues by avidin. J. Raman Spectrosc. 1998, 29, 229-236. [CrossRef]

29. Krimm, S.; Bandekar, J. Vibrational spectroscopy and conformation of peptides, polypeptides, and proteins. Adv. Protein Chem. 1986, 38, 181-364. [CrossRef]

30. Altose, M.D.; Zheng, Y.; Dong, J.; Palfey, B.A.; Carey, P.R. Comparing protein-ligand interactions in solution and single crystals by Raman spectroscopy. Proc. Natl. Acad. Sci. USA 2001, 98, 3006-3011. [CrossRef]

31. Carey, P.R. Biochemical Applications of Raman and Resonance Raman Spectroscopies; Academic Press: Cambridge, UK, 1982; ISBN 9780121596507.

32. Harada, I.; Miura, T.; Takeuchi, H. Origin of the doublet at 1360 and $1340 \mathrm{~cm}-1$ in the Raman spectra of tryptophan and related compounds. Spectrochim. Acta. Part A Mol. Spectrosc. 1986, 42, 307-312. [CrossRef]

33. David, C.C.; Jacobs, D.J. Principal component analysis: A method for determining the essential dynamics of proteins. Methods Mol. Biol. 2014, 1084, 193-226. [CrossRef]

34. Thomas, G.J. Raman spectroscopy of protein and nucleic acid assemblies. Annu. Rev. Biophys. Biomol. Struct. 1999, 28, 1-27. [CrossRef]

35. Nar, H.; Messerschmidt, A.; Huber, R.; Van De Kamp, M.; Canters, G.W. Crystal structure of Pseudomonas aeruginosa apo-azurin at 1.85 A resolution. FEBS Lett. 1992, 306, 119-124. [CrossRef]

36. Natan, E.; Baloglu, C.; Pagel, K.; Freund, S.M.V.; Morgner, N.; Robinson, C.V.; Fersht, A.R.; Joerger, A.C. Interaction of the p53 DNA-binding domain with its n-terminal extension modulates the stability of the p53 tetramer. J. Mol. Biol. 2011, 409, 358-368. [CrossRef]

37. Wen, Z.Q. Raman spectroscopy of protein pharmaceuticals. J. Pharm. Sci. 2007, 96, 2861-2878. [CrossRef]

38. Apiyo, D.; Wittung-Stafshede, P. Unique complex between bacterial azurin and tumor-suppressor protein p53. Biochem. Biophys. Res. Commun. 2005, 332, 965-968. [CrossRef]

39. Uversky, V.N.; Oldfield, C.J.; Midic, U.; Xie, H.; Xue, B.; Vucetic, S.; Iakoucheva, L.M.; Obradovic, Z.; Dunker, A.K. Unfoldomics of human diseases: Linking protein intrinsic disorder with diseases. BMC Genom. 2009, 10, S7. [CrossRef]

40. Yamada, T.; Christov, K.; Shilkaitis, A.; Bratescu, L.; Green, A.; Santini, S.; Bizzarri, A.R.; Cannistraro, S.; Gupta, T.K.; Beattie, C.W. p28, A first in class peptide inhibitor of cop1 binding to p53. Br. J. Cancer 2013, 108, 2495-2504. [CrossRef] 
41. Minde, D.P.; Dunker, A.K.; Lilley, K.S. Time, space, and disorder in the expanding proteome universe. Proteomics 2017, 17, 1600399. [CrossRef]

42. Kengne-Momo, R.P.; Daniel, P.; Lagarde, F.; Jeyachandran, Y.L.; Pilard, J.F.; Durand-Thouand, M.J.; Thouand, G. Protein Interactions Investigated by the Raman Spectroscopy for Biosensor Applications. Int. J. Spectrosc. 2012, 2012, 1-7. [CrossRef]

43. Domenici, F.; Bizzarri, A.R.; Cannistraro, S. Surface-enhanced Raman scattering detection of wild-type and mutant p53 proteins at very low concentration in human serum. Anal. Biochem. 2012, 421, 9-15. [CrossRef] [PubMed]

44. Ortiz, C.; Zhang, D.; Xie, Y.; Ribbe, A.E.; Ben-Amotz, D. Validation of the drop coating deposition Raman method for protein analysis. Anal. Biochem. 2006, 353, 157-166. [CrossRef] [PubMed]

45. Krafft, C.; Hinrichs, W.; Orth, P.; Saenger, W.; Welfle, H. Interaction of Tet repressor with operator DNA and with tetracycline studied by infrared and Raman spectroscopy. Biophys. J. 1998, 74, 63-71. [CrossRef]

46. Yang, H.; Yang, S.; Kong, J.; Dong, A.; Yu, S. Obtaining information about protein secondary structures in aqueous solution using Fourier transform IR spectroscopy. Nat. Protoc. 2015, 10, 382-396. [CrossRef] [PubMed]

(C) 2019 by the authors. Licensee MDPI, Basel, Switzerland. This article is an open access article distributed under the terms and conditions of the Creative Commons Attribution (CC BY) license (http://creativecommons.org/licenses/by/4.0/). 